\title{
Teleconnections between the North Atlantic SST and Mediterranean rainfall
}

\author{
J. Quereda, E. Montón and J. Escrig \\ Climate laboratory, Interuniversity institute of geography, Universitat Jaume I; Avda. Sos Baynat s/n, 12071 Castelló de La \\ Plana
}

Received: 12-IV-2010 - Accepted: 2-II-2011 - Translated version

Correspondence to: quereda@ $@$ his.uji.es

\begin{abstract}
This work analyzes the energy teleconnections observed between Sea Surface Temperature anomalies in the North Atlantic and the cyclogenesis of the western Mediterranean basin. The basin has a high edge and in its central part there is a warm and evaporating sea that is crucial for energy exchanges that are key for its autarkic climatology. This could be the reason for not having observed any signification in the teleconnections between Mediterranean rainfalls and the North Atlantic Oscillation index. However, the energy deficits registered in the polar oceanic basins seem to be the trigger of the Mediterranean cyclogenetic activity through the draining of polar cold air over the warm Mediterranean waters. Simultaneously, the latent heat included in Mediterranean cyclogenesis is injected and diffused in high circulation to restore the hemispheric thermal balance. These processes have been systematically analyzed since 1981, when the registers of the sea university station started to show the intensity of air-sea interactions in the western Mediterranean basin.
\end{abstract}

Key words: teleconnections, SST, polar, Mediterranean, latent heat

\section{Introduction}

The covariances of the NAOi (North Atlantic Oscillation index) and SST (Sea Surface Temperature) analyzed in the polar waters of the North Atlantic show the important role that hemispheric energy balance plays in generating atmospheric circulation patterns. Atmospheric forcing of the SST through latent heat fluxes (Rodwell and Folland, 2002) is developed in the closed atmosphere-ocean model HadCM3 from the Hadley Center (IPCC). The patterns of the GCA (General Circulation of the Atmosphere) are closely linked to atmosphere-ocean interactions (Watanabe and Kimoto, 2006). Meridian circulations, with enhanced baroclinicity and cyclogenetic waves, show great sensitivity to the negative phases of the North Atlantic Oscillation (NAO) (Feldstein, 2007; Strong and Davis, 2007). In contrast, positive SST anomalies over latitudes of $40^{\circ} \mathrm{N}$ seem to excite the positive phase of the NAO, with a reduction of cyclogenetic waves and accumulation of cold air in northern latitudes. This implies also a reduction in the intensity and fre- quency of blocking situations with an average of six days compared to the eleven days of the negative NAO (Bueh and Nakamura, 2007).

The aim of our work on the western Mediterranean basin is part of this order of knowledge. The NAOi resonance is not significant there (Martín-Vide and FernándezBelmonte, 2001), and other teleconnections may be more decisive, such as the WeMOi (Western Mediterranean Oscillation index) (Martín-Vide and López-Bustins, 2006). Indeed, a basin orographic configuration, where the Atlantic systems experience a strong angular momentum transfer over the surrounding mountains (Egger and Peter-Hoinka, 2008) and an extraordinarily convective seafloor, determine a very original and autarkic area. Consequently, it is legitimate to question the role that SST anomalies in the North Atlantic, as a reflection of the hemispheric energy status, can have on the drainage of polar air over the warm waters of the Mediterranean to enable convective cyclogenesis.

The basin is characterized by a rainfall regime determined by explosive cyclogenesis in summer and autumn. 


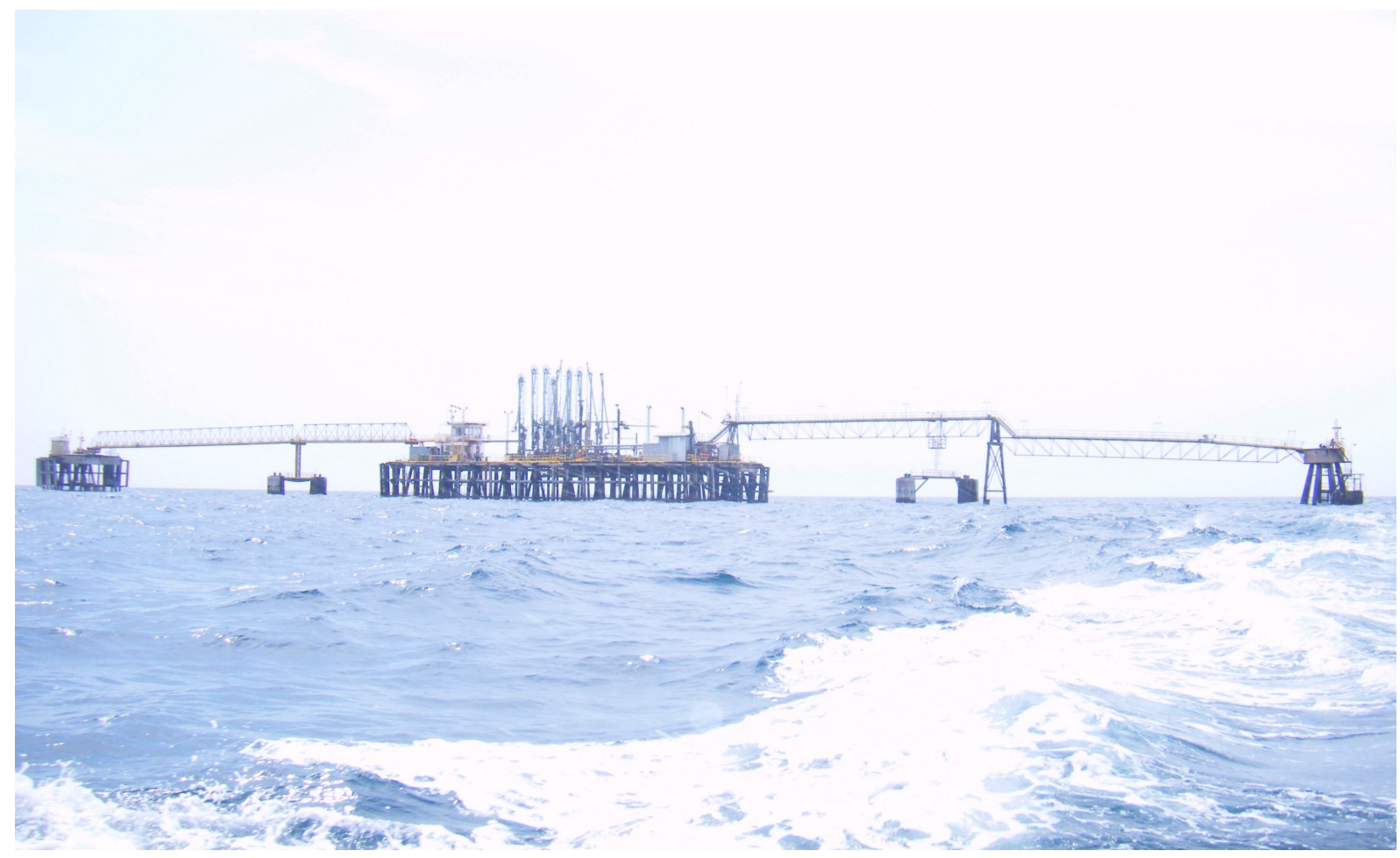

Figure 1. Marine observatory of the Universitat Jaume I, in the left end of the BPOil platform, over contour line of -20 meters, (39 $56^{\prime} 42^{\prime \prime} \mathrm{N}$ and $00^{\circ} 01 ' 36$ 'E), (2001-2008).

Analyses developed in previous works have shown that these circulation anomalies were associated with similar anomalies of the hemispheric energy distribution and in particular, with SST anomalies in the western Mediterranean. This is a teleconnection that this work tries to confirm through the high correlations obtained between regional rainfall (1950-2008) and historical (1880-2009) and regional (1950-2005) series of València and Murcia with the SST anomalies in the North Atlantic.

Thus, the main objective of this study was to analyze the cyclogenetic resonances of the Mediterranean atmosphere with the SST anomalies in the North Atlantic. In this framework we have proposed a simple theory that explores the physical basis of this resonance as hemispheric energy realignment. This process is linked in large part to the heat transport encompassed in the cyclogenesis of the western Mediterranean basin, without diminishing that these very physical bases may suggest further directions of analysis, that are safer, in more complex general circulation models.

\section{Methodology and techniques}

Analysis of air-sea interactions as a key process in Mediterranean climatology has helped to establish the foundations of the formulated theory. The analysis has been based on the knowledge of the formation of the surface ther- mal field in the western Mediterranean basin through records of the marine university observatory on the BPOil platform $\left(39^{\circ} 56^{\prime} 42^{\prime \prime} \mathrm{N}\right.$ and $\left.00^{\circ} 01^{\prime} 36^{\prime \prime} \mathrm{E}\right)$ (Figure 1). The observatory is in a unique location on the oil platform BPOil (300 m long and $\mathrm{E}-\mathrm{W}$ oriented), at $3 \mathrm{~km}$ from the coast, $12 \mathrm{~m}$ above sea level and above contour line of $-20 \mathrm{~m}$. The observatory, operating conventionally since 1981 , has been fully automated since mid-2000 with two CASELLA-DAVIS stations. These stations consist of the typical equipment of meteorological sensors plus three temperature soundings for water temperature at -1 and $-3 \mathrm{~m}$, and more recently at $-7 \mathrm{~m}$. The data are transmitted to the Applied Climatology Station at the Universitat Jaume I.

The sharp seasonal contrast of the thermal field is key for some very determining convective processes of Mediterranean cyclogenesis and its originality, processes that, at the same time, have shown their link with the same dynamics of the climate system, governed by the need for meridian thermal transfer. This transfer, the true engine of the GCA, has been established by varying the cycle index, $I(\lambda)$ where $\lambda$ is the geographical latitude, through the records of the geostrophic wind speed and the atmospheric temperature gradient $30-60^{\circ}$ at $700 \mathrm{hPa}$, over the North Atlantic. This is an analysis based on the dynamic and thermal average over a longitudinal $\operatorname{arch}\left(12.5^{\circ} \mathrm{E}-17.5^{\circ} \mathrm{W}\right)$. This methodology provides a more representative value for the hemispheric energy with respect to that used in the indexes NAOi, PNA (Pacific/North American) and others, based on two or four 


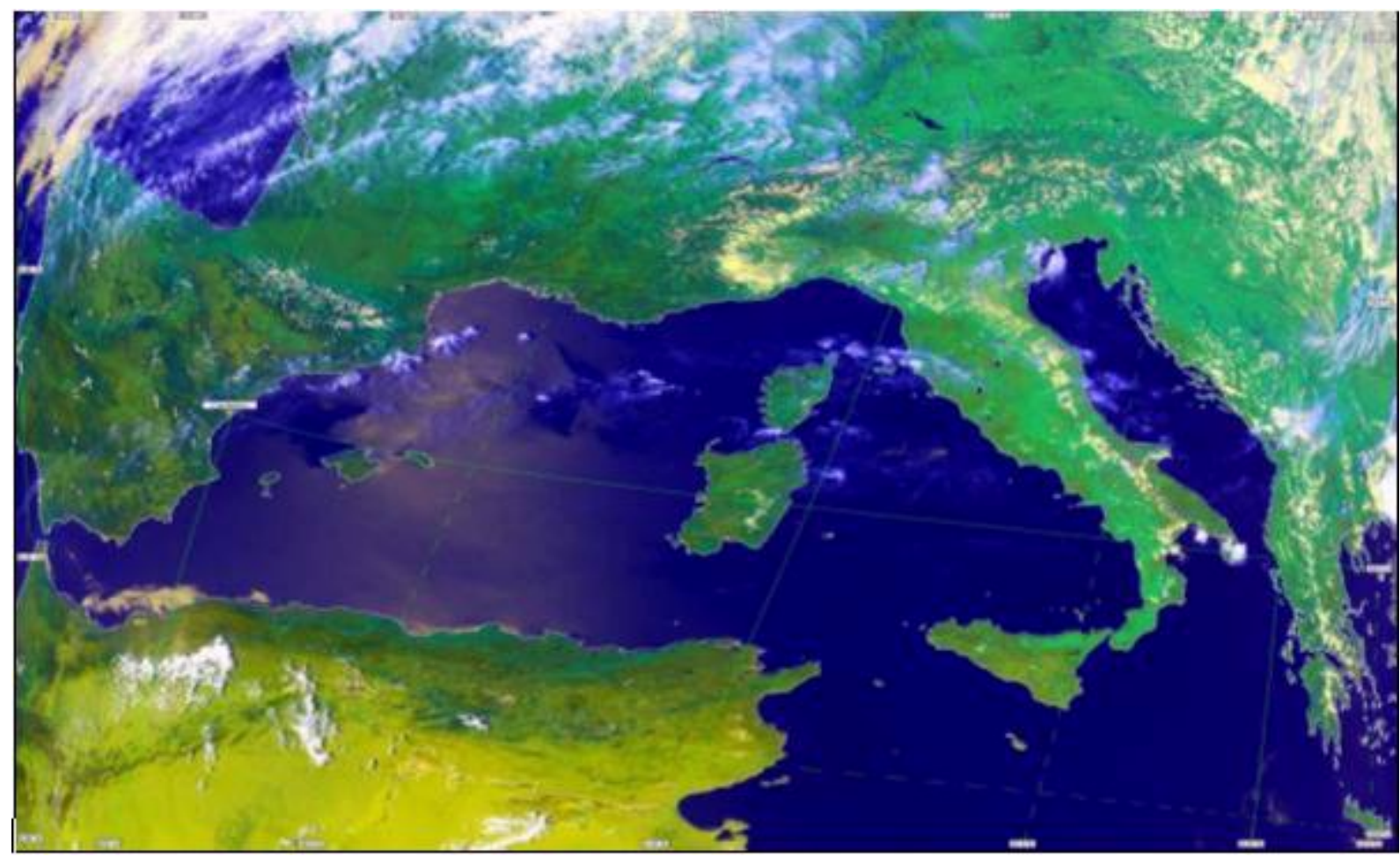

Figure 2. The western Mediterranean basin is configured as a high edge basin where the air layers are not easy to renew. The African aerosol, visible in the image, is an exponent of the continental tropical nature that gives rise to the uniform air mass over the sea (NOAA-16 image, june 26 2004, visible channel, Universitat Jaume I).

points of reference. These indexes, in the case of NAOi, would be questioned, in terms of the forecast of the climate change models of an intensification and movement to the northeast of the two large North Atlantic pressure centers (Zeng-Zeng and Zhaohua, 2004). This is without minimizing the widespread recognition that the current analyses give to the coupling of GCA patterns with the NAO phases over the North Atlantic (Gulev et al., 2000; Stephenson et al., 2000; Marshall et al., 2002; Trigo et al., 2004; Andersson et al., 2010).

In this line of analysis, recent research has shown that the resonances of the atmosphere to SST anomalies provide different responses on a global scale (Colin de Verdière and Blanc, 2001). Specifically, in the North Atlantic, the seasonal correlations have shown a great significance during the winter-spring semester. Even these teleconnections between winter SST variability and atmospheric forcing have been verified in Eastern Europe through the index EAWR (East Atlantic-West Russia) (Kazmin et al., 2009). We have tried to verify these resonances on the western Mediterranean basin, by comparing the cycles of SST and the temperature in the main polar and subpolar observatories of the Atlantic with those of the Mediterranean rainfall (average of annual rainfall values at the first order observatories of Murcia, Alacant, València and Castelló).

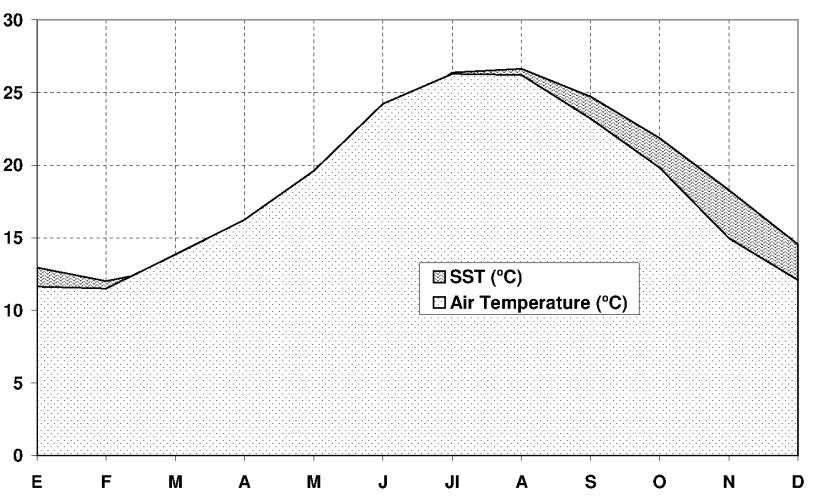

Figure 3. Average temperatures for 2001-2008, of the air (observatory of the Universitat Jaume I) and of the SST (sea observatory of the Universitat Jaume I).

\section{Geographical factors}

The western Mediterranean basin is a key zone with regards to air-sea interactions. Both the prolonged conditions of atmospheric stability and especially the genesis and evolution of its intense weather disturbances are determined by the inhibition or the greater or lesser intense development 


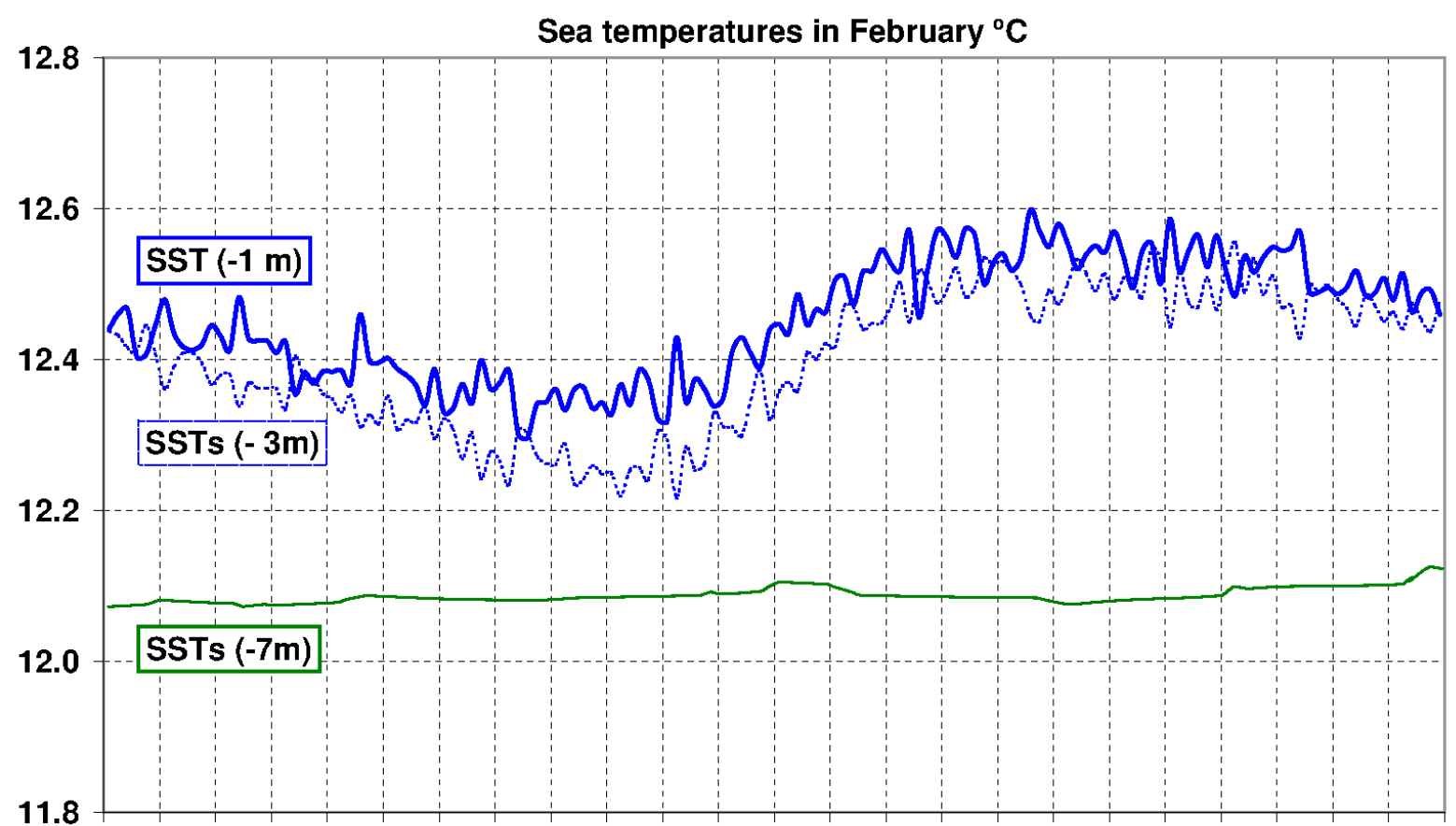

$\begin{array}{llllllllllllllllllllllll}00 & 01 & 02 & 03 & 04 & 05 & 06 & 07 & 08 & 09 & 10 & 11 & 12 & 13 & 14 & 15 & 16 & 17 & 18 & 19 & 20 & 21 & 22 & 23\end{array}$

Figure 4. The vertical thermal profile of February shows the constitution of a surface layer with a large homothermia. The daily average thermal gradient between the surface and the $-7 \mathrm{~m}$ contour line is only $0.2 / 0.4^{\circ} \mathrm{C}$. (SST, surface temperature, at $-1 \mathrm{~m}$; SSTs, subsurface temperature, at -3 and $-7 \mathrm{~m}$ ). Averages for the period 2001-2008 (marine university observatory).

of convective processes that are generated within the marine basin. Processes that generate a climate with a unique character manifested especially in the predominance of stable atmospheric conditions and the scarcity and irregularity of their disturbances.

This singularity, as demonstrated by Jansà Guardiola (1951, 1966) and recognized in the Rome Symposium on Meteorology of the Mediterranean Basin (1958), is due to the prominent role that geographical factors play in its genesis. Among these factors, the orographic configuration in the shape of a basin should be specially considered (Figure 2).

\section{Marine thermal field}

In the center of the Mediterranean basin, the sea mass is key in climate processes, due to its warm temperatures, high specific heat and convective and evaporative potential (Noussier et al., 2008). So, as a first example of this, the coastline presents a strong thermal discontinuity. In this regard it is enough to compare the mean annual air temperature in Castelló, $17^{\circ} \mathrm{C}$, with the average thermal state of the water at $2.5 \mathrm{~km}$ from the coast, $19^{\circ} \mathrm{C}$. This land-sea thermal gradient is further enhanced by the one existing between the sea surface and the air layer located above it at 10 meters high, $17.9^{\circ} \mathrm{C}$. Both thermal contrasts, horizontal and vertical, are much more pronounced from late summer to early winter (Figure 3). Thus, the average temperature of the sea surface from October to December is $17.9^{\circ} \mathrm{C}$, while the temperature of the layer of air located on top of it is $15.4^{\circ} \mathrm{C}$. This gradient is already a potential convectivity factor that is present in most of the Mediterranean atmospheric disturbances.

Such temperature field will be decisive for energy exchanges, air-sea, which are key for Mediterranean climatology. Thus, during the fall and winter the SST tends to be higher than that of the air. This generates an active heat emission into the atmosphere with surface water cooling (Figure 4). The subsidence of sea water helps create a deep homothermia. The average daily winter temperature range of SST (sea observatory of the Universitat Jaume I (2001 2008 ) is $0.32^{\circ} \mathrm{C}$, compared to $0.47^{\circ} \mathrm{C}$ in summer.

On the other hand, during the summer, intense solar radiation and high ambient temperatures, under a persistent situation of anticyclonic stability, limit convective turbulence. The thermocline appears on the very surface and the active layer involved in the exchanges with the atmosphere becomes very thin. Consequently, the warming is more intense at the superficial volume of the water (Figure 5). Therefore, the current observations have detected that the highest variability in the formation of surface thermal anomalies is registered during summer. Thus, analysis of variations on surface thermal anomalies of the North Atlantic and North Pacific have shown that the maximum occurs in the warm season be- 
21.1

Sea temperatures in October ${ }^{\circ} \mathrm{C}$

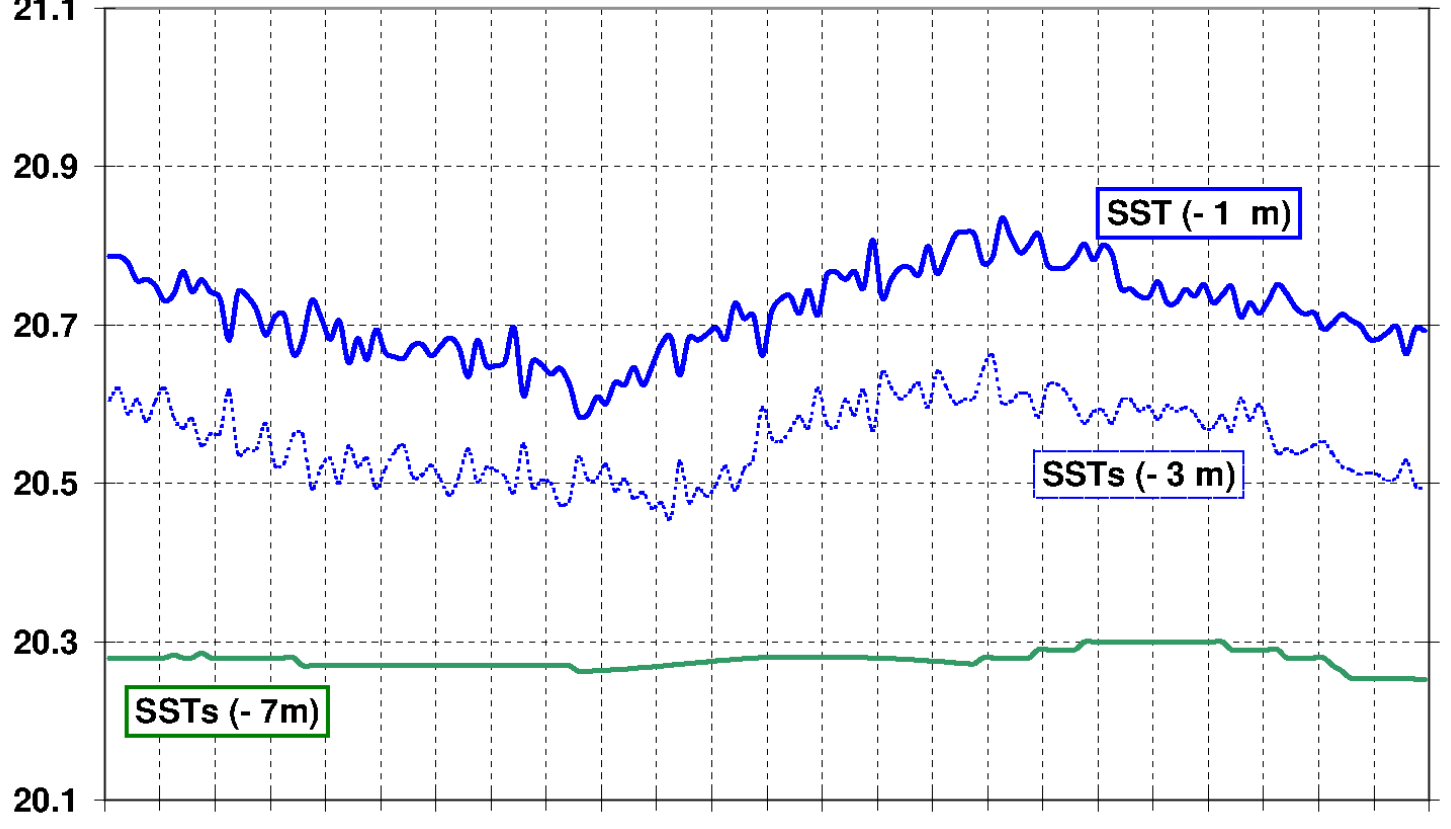

22.1

21.7

21.5

21.3

Figure 5. The vertical thermal profile during October after the summer formation of the thermocline. The daily average thermal gradient between the surface and the $-7 \mathrm{~m}$ contour line is $1.3^{\circ} \mathrm{C}$. Averages for the period 2001-2008 (marine university observatory). The $y$-axis at the left hand side is for the $-7 \mathrm{~m}$ curve, the right hand side is fore the other two.

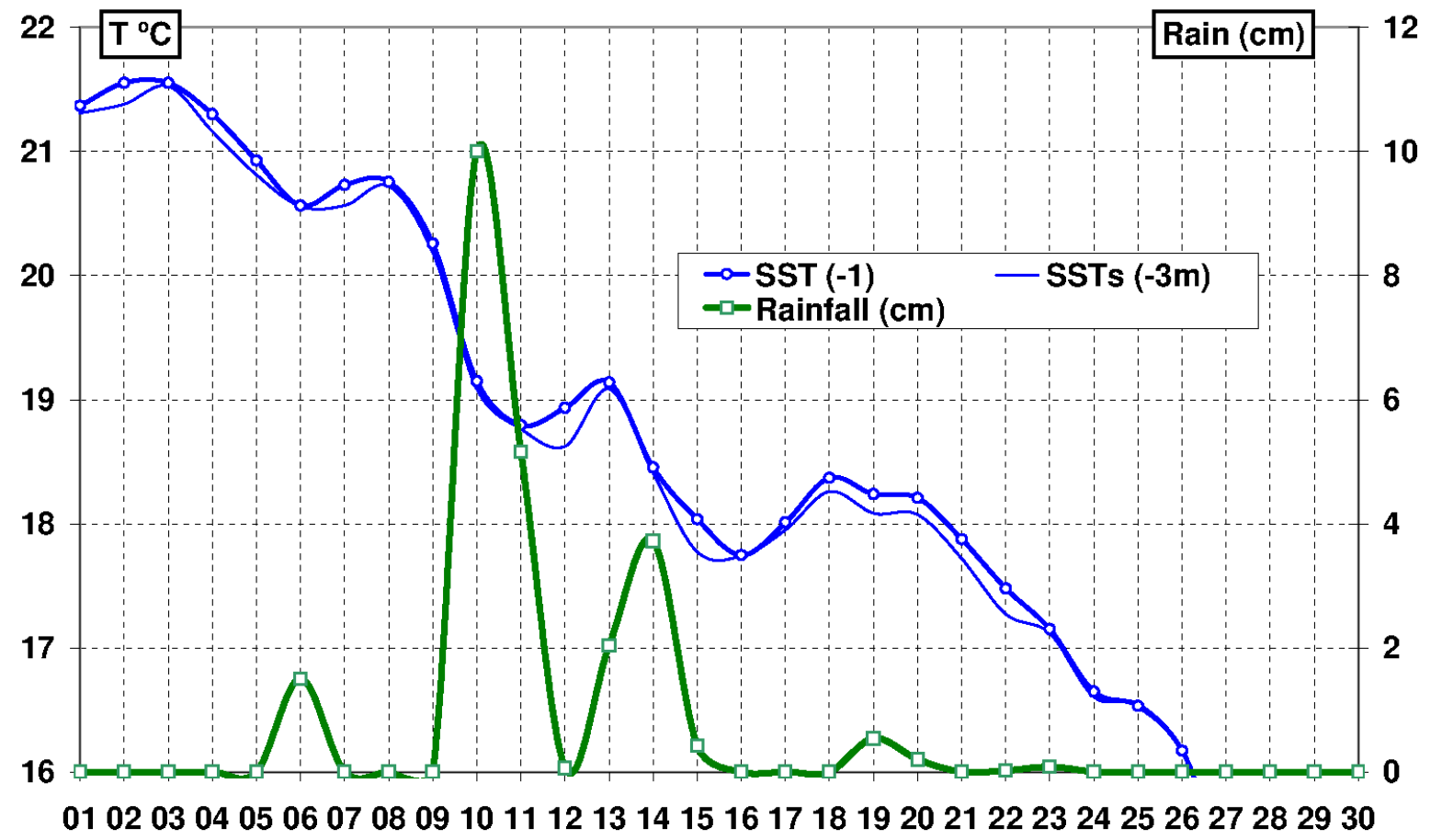

Figure 6. Air-sea interactions during November 2005. The major cyclogenesis of day 10 is preceded by the intensification of the evaporative processes from 48 hours before (marine university observatory). 


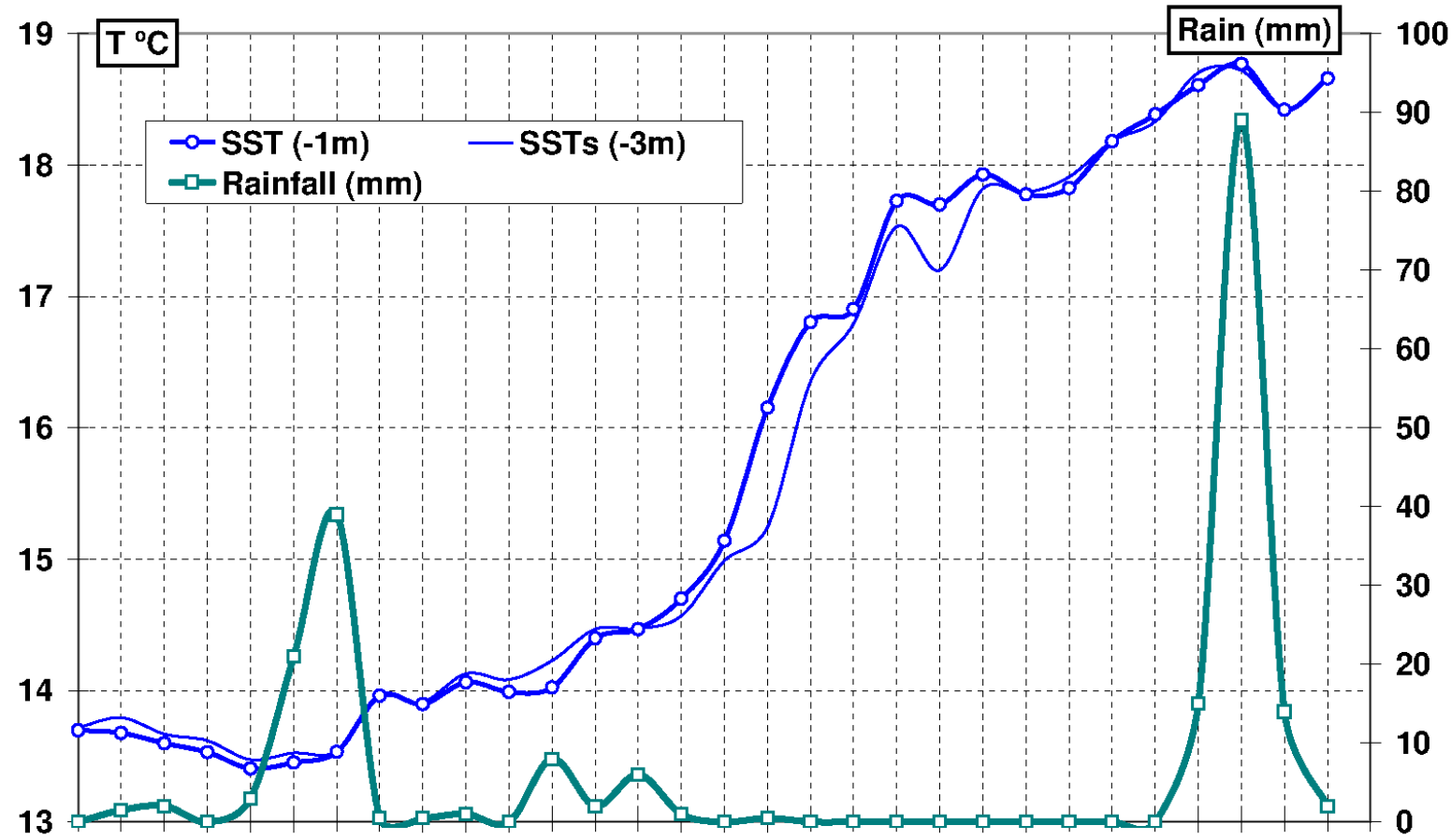

01020304050607080910111213141516171819202122232425262728293031

Figure 7. Air-sea interactions during April 2007. The major cyclogenesis of day 28 is preceded by the intensification of evaporative processes (marine university observatory).

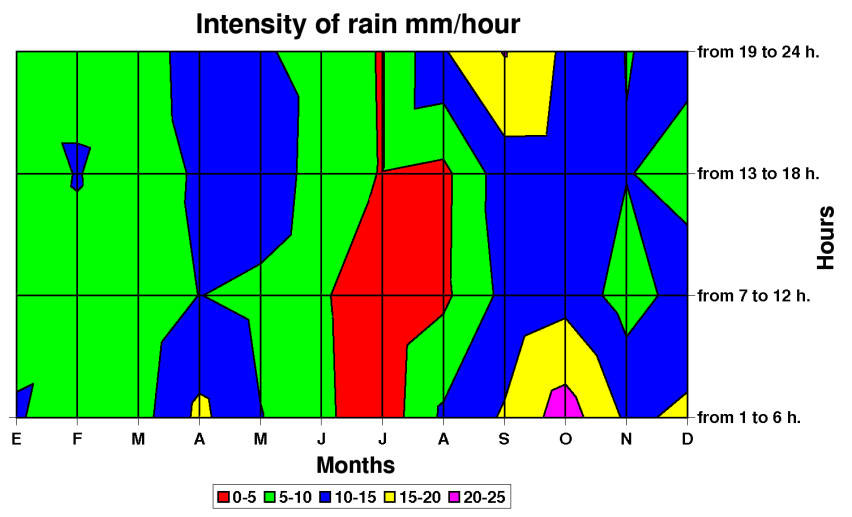

Figure 8. Isopleths of the hourly intensity, seasonally and daily distribution. The values come from two series: observatory of Castelló (INM-AEMET bands) (1985-2000) and university observatory (automatic station, 2001-2005).

tween July and September, as in the western Mediterranean, where the summer variation, up to $3^{\circ} \mathrm{C}$, is twice the winter variation (Quereda-Sala, 1986; Alekseev and Bagryantsev, 1987).

The cumulated positive anomalies of the SST can contribute to the polar air drainage into the western Mediterranean basin, and simultaneously act as a basic factor of the air-sea interactions. Areas with positive SST anomalies stand as highly convective surfaces with respect to the overlying air layer. These same observations allow to define a threshold for strong convection when values of air-sea thermal gradient are higher than 4 or $5^{\circ} \mathrm{C}$. Intense evaporation precedes major cyclogenesis. The sea thermal soundings show a significant cooling with sinking of surface water and deeper water lift (Figures 6 and 7).

In short, the formation of this surface thermal field of the sea is crucial for some energy exchanges that are key in Mediterranean climatology. In fact, it is not a pure random effect that $70 \%$ of the rain with an intensity exceeding $60 \mathrm{~mm}$ in 24 hours is concentrated in the months of September to November and all extreme rainfall events with an intensity higher than 20-25 mm hour ${ }^{-1}$ are located in those months during the night and early morning hours (Figure 8).

\section{Atmospheric factors}

The thermoconvective effect of the sea surface is not the sole factor in regional climatology. Its true role is exercised through constant interaction with the overlying atmosphere. They are processes whose seasonality show their connection with the same dynamics of the climate system. This system appears to be governed by a basic need for meridian thermal transfer (Vonder Haar and Oort, 1973). This is the fun- 


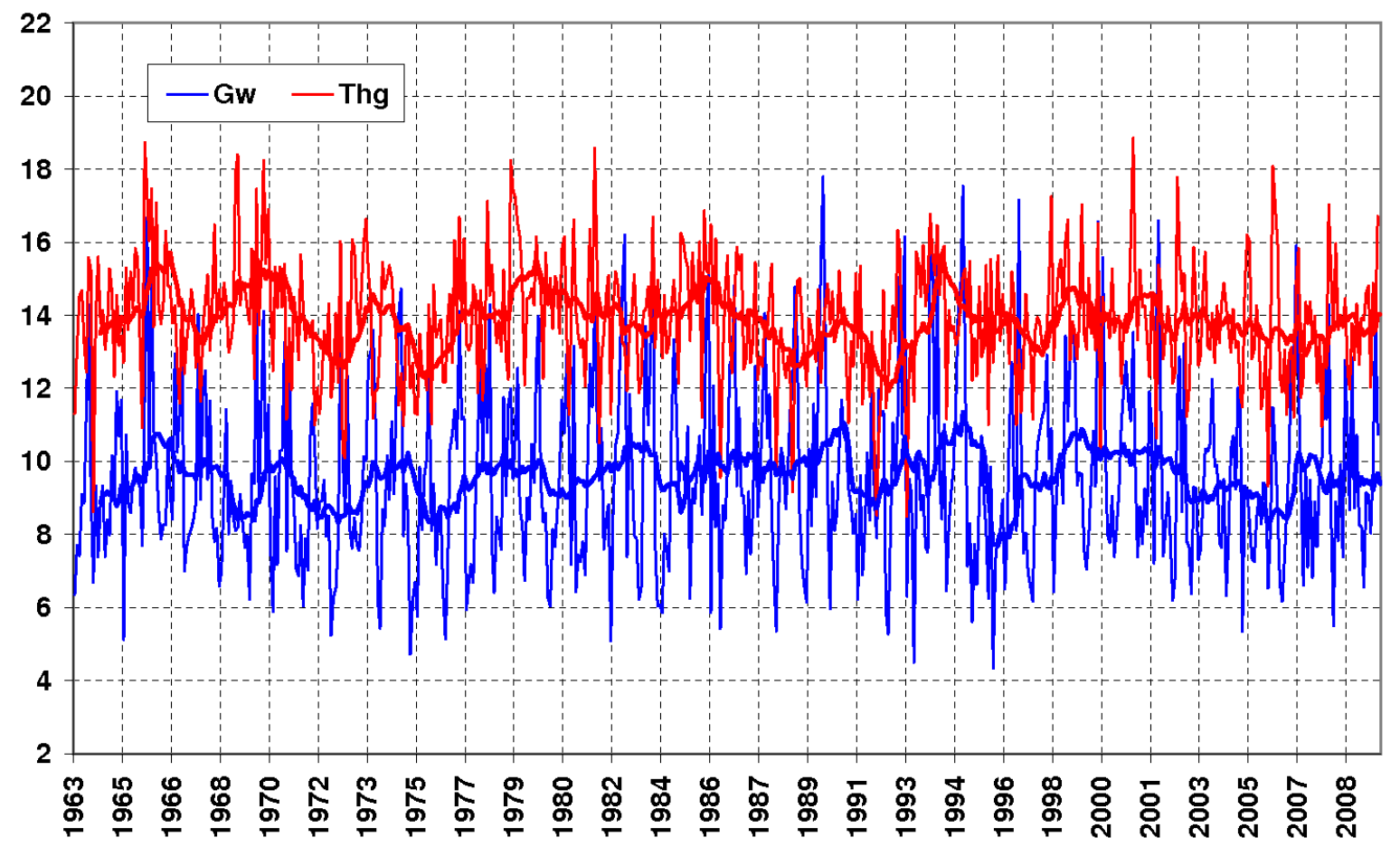

Figure 9. Monthly averages of the geostrophic wind speed $(G w)$ in $\mathrm{m} \mathrm{s}^{-1}$ and of the thermal gradient $\left(\right.$ Thg in $\left.{ }^{\circ} \mathrm{C}\right) 30^{\circ}-60^{\circ} \mathrm{N}$ at $700 \mathrm{hPa}$ above the Atlantic. The figure shows, in monthly and moving averages, $(r=0.61)$ that the situations of high $I(\lambda)$ are not favorable for the hemispheric distribution of energy, but, on the contrary, they seem to increase the thermal gradients (NCAR, 2010).

damental theorem of circulation, discovered by V. Bejerknes in 1897, and more recently formulated in terms of the NAO (Visbeck et al., 2001). In a baroclinic field, the intensity of a thermal circulation depends only on the number of solenoids, here a function of the meridian thermal difference. Thus, the degree of intensity of these transfers can be shown through the cycle index, expressed by several expressions. One of the most significant formulas, which suggests that large drainage or atmospheric disturbances ensue when the cycle index, $I(\lambda)$, corresponds to the conditions (Lejenas and Okland, 1983):

$I(\lambda)=H(\lambda)_{40 N}-H(\lambda)_{60 N}<0$

$I(\lambda-10)+I(\lambda)+\frac{I(\lambda+10)}{3}<0$

where $\lambda$ is the geographical longitude and $H$ is the geopotential at $500 \mathrm{hPa}$. In our analysis $H$, is the average of the parallels $30^{\circ} \mathrm{N}$ and $60^{\circ} \mathrm{N}$ of the longitudinal coordinate arch $12.5^{\circ} \mathrm{E}-17.5^{\circ} \mathrm{W}$.

This formula, like other mathematical expressions, reflects the value of thermal exchanges between polar air and tropical air. These exchanges can be interpreted as the driving force of general circulation that, in the middle troposphere, varies between a high index (mainly zonal) and a low index (mainly meridian). The oscillation from a type of circulation to another and its alternance during periods of three to six weeks, forms what is called the cycle index (Stringer, 1972). The latter could be equivalent to the more recently introduced NAOi, although it opposes the energy state (geopotential) on the oceanic length of the North Atlantic between the parallels $60^{\circ} \mathrm{N}$ and $40^{\circ} \mathrm{N}$ when considering the IcelandAzores dipole.

Consistently with this oscillation of the cycle index during periods of high index thermal differences between polar and tropical latitudes are well marked. This determines the existence of a western Atlantic flow, wide and well marked zonally, whose intensity contributes to containing the cold air masses at high latitudes and the warm masses at low latitudes. This atmospheric situation during periods of high index value is generally characteristic of times of stability. However, the prolongation of such high index situations usually generates an increase of meridian thermal gradients by the accumulation of cold air at high latitudes and warm air in the middle and lower ones (Figure 9). The correlation between both variables is 0.61 .

During low rate cycles, the winds from the West, in the middle and upper troposphere, describe trajectories lower in latitude with more or less marked waves, so that the positive and negative thermal anomalies overlap. The zonal rate of circulation or speed of westerly winds in middle latitudes (Kidson, 1985), goes from values always higher than 15- 


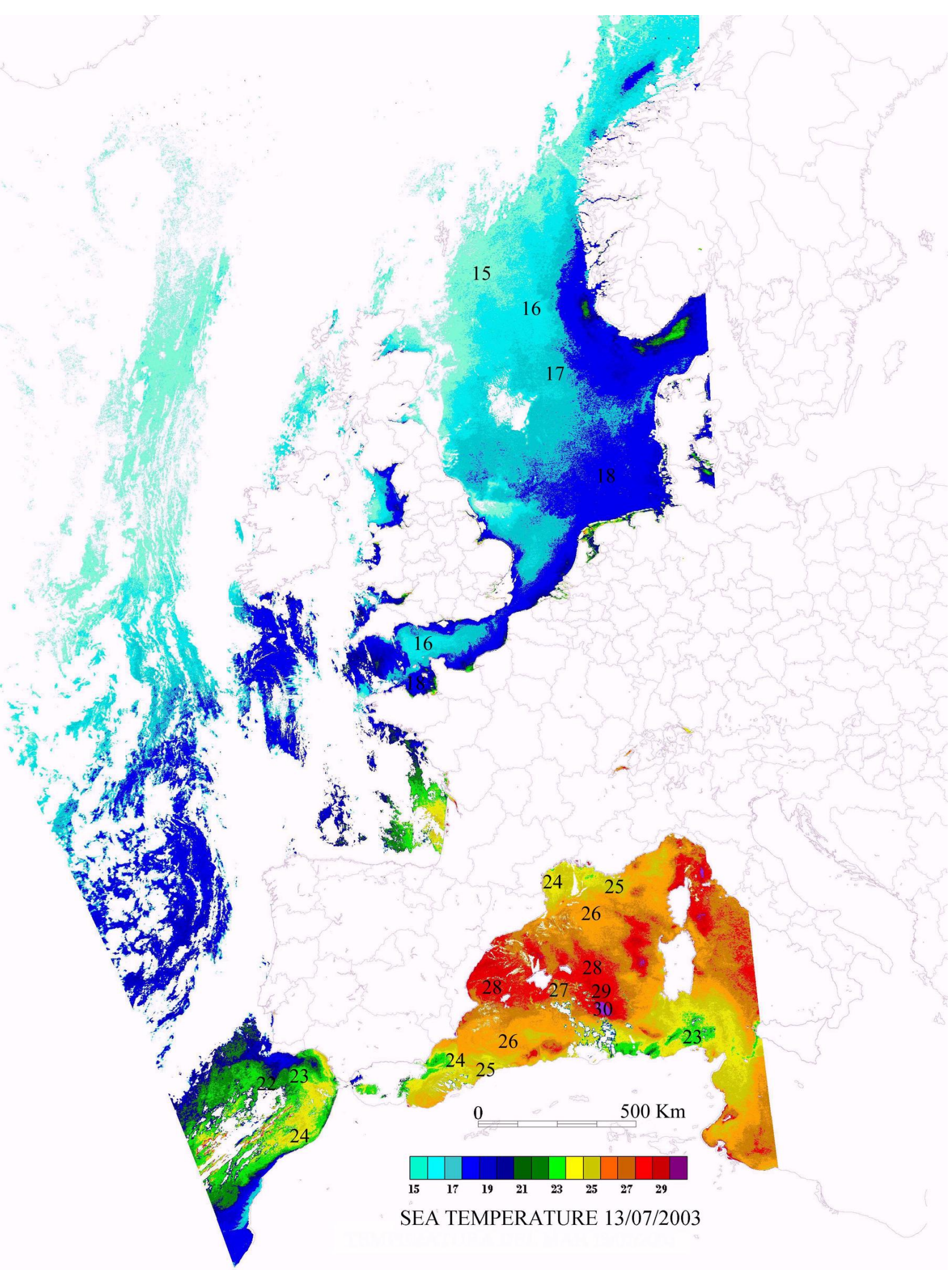

Figure 10. The significant hemispheric thermal gradient existing in mid July 2003 (thermography obtained on the NOAA image 13/07/2003) was a precursor for the low zonal index situation with considerable rainfall over the Mediterranean coastline (climatology laboratory, Universitat Jaume I). 


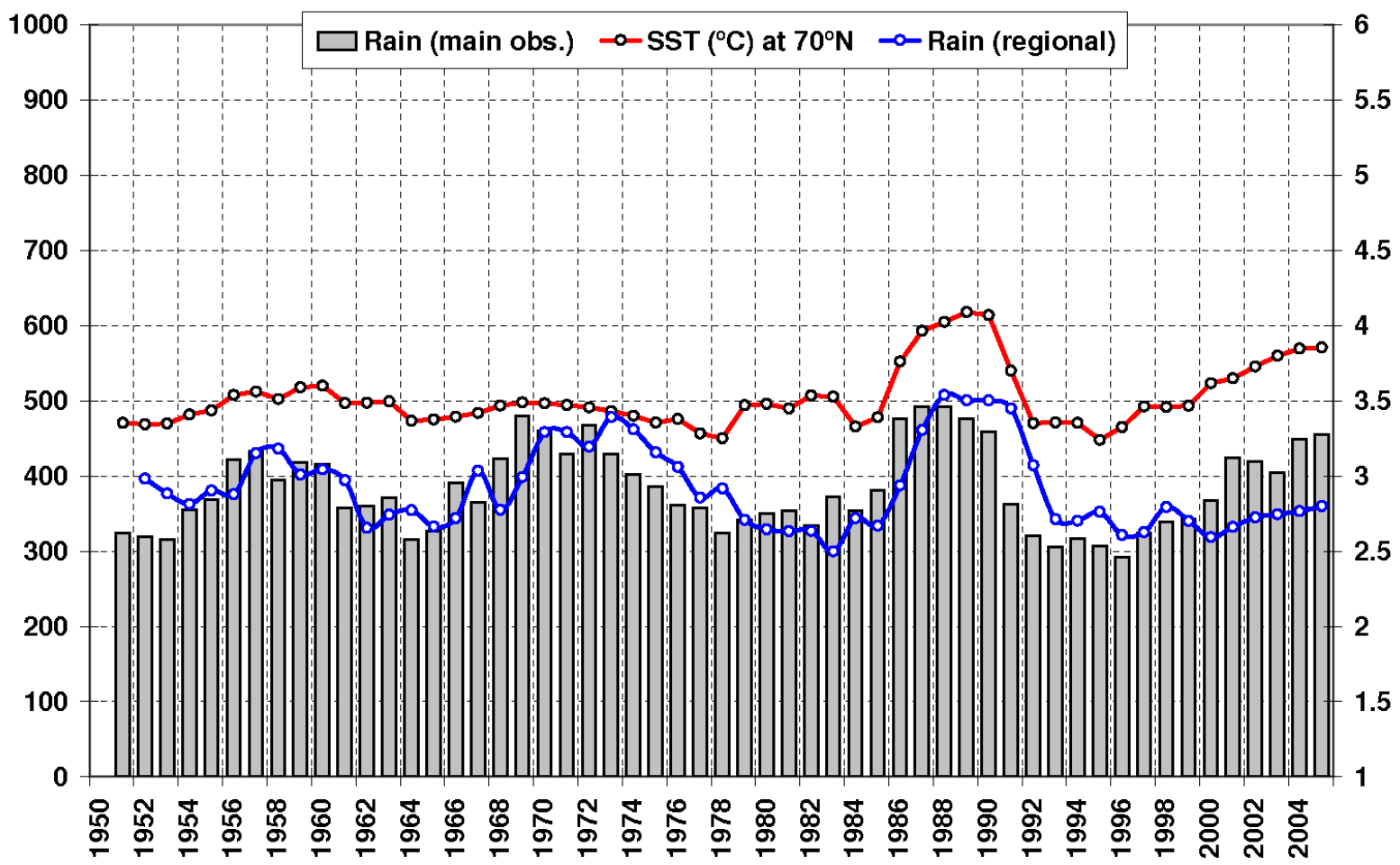

Figure 11. Thermal evolution (smoothed, in red) of the winter SST (December-February) at $70^{\circ} \mathrm{N}$ (average $12.5^{\circ} \mathrm{E}$ to $17.5^{\circ} \mathrm{W}$ ) from the HadSST2 data set (Rayner et al., 2006) and from the Mediterranean annual rainfall, slowed down, in Rain (main obs.), for the first order observatories of Murcia, Alacant, València and Castelló, and Rain (regional), annual average of fifty observatories with records longer than 50 years (INM-AEMET) homogenized with the method Standard Normal Homogeneity Test. Left axis for rainfall, right axis for SST.

$16 \mathrm{~m} \mathrm{~s}^{-1}$ of monthly average to weak values under $8 \mathrm{~m} \mathrm{~s}^{-1}$, also of monthly average, according to the observations and to the mathematical expression:

$V=-\frac{g}{f} \frac{H_{2}-H_{1}}{Y_{2}-Y_{1}}$

a function where $V$ is the geostrophic wind speed, $H_{1}$ and $H_{2}$ the mean geopotential along the geographic parallels $35^{\circ} \mathrm{N}$ and $55^{\circ} \mathrm{N}$ on isobaric surfaces of 700 or $500 \mathrm{hPa}$, with $Y_{1}$ and $Y_{2}$ as latitudinal coordinates, with $f$ as the Coriolis parameter, and $g$ the acceleration of gravity.

Thus, when the accumulation of cold air at polar latitudes or of warm air in the tropics or the Mediterranean basin is excessive, the atmosphere behaves like a giant condenser that is discharged either with cold air eruptions or with warm ridges that activate the blockings. These are the mechanisms that, during situations with low zonal circulation index, cause the disruption of the typical situations of stability by unstable situations and rainfall on the eastern side of Spain.

Large general circulation anomalies such as explosive cyclogenesis are the result of similar anomalies in the distribution of energy (Namias, 1987 and 1989). This suggests that large anomalies in the western Mediterranean SST could be an alert for cyclogentic events (Quereda-Sala and Montón, 1994, 1989a and 1989b). Therefore we can suggest the hypothesis that the energy anomalies detected by the SST could be at the basis of Mediterranean rainfall cycles according to the mechanisms mentioned. These hypotheses and processes have been reaffirmed through the analysis of the more intense rainfall events on the Spanish Mediterranean area during the past three decades. All major summer and autumn cyclogenesis, with more than $50 \mathrm{~mm} \mathrm{day}^{-1}$ of rainfall over large areas of the regions of València and Murcia, were preceded by significant anomalies in the air-sea interface. These anomalies consisted in SST values over $26^{\circ} \mathrm{C}$ and air-sea gradients of 5 to $6^{\circ} \mathrm{C}$. Especially the great cyclogenesis from 4 to 7 September 1989, with rainfall over $150 \mathrm{~mm}$ in Castelló, recorded $29^{\circ} \mathrm{C}$ in the SST of August (Quereda-Sala, 1990). Also, in most of them the thermal conditions of the air-sea interface, observed on a large scale, showed significant hemispheric anomalies. The most characteristic one is a significant cooling of SST in the subpolar North Atlantic waters. This energy anomaly can contribute not only to the drainage of cold air over the Mediterranean basin, but, through the increase of air-sea thermal gradients, it can trigger convection. 


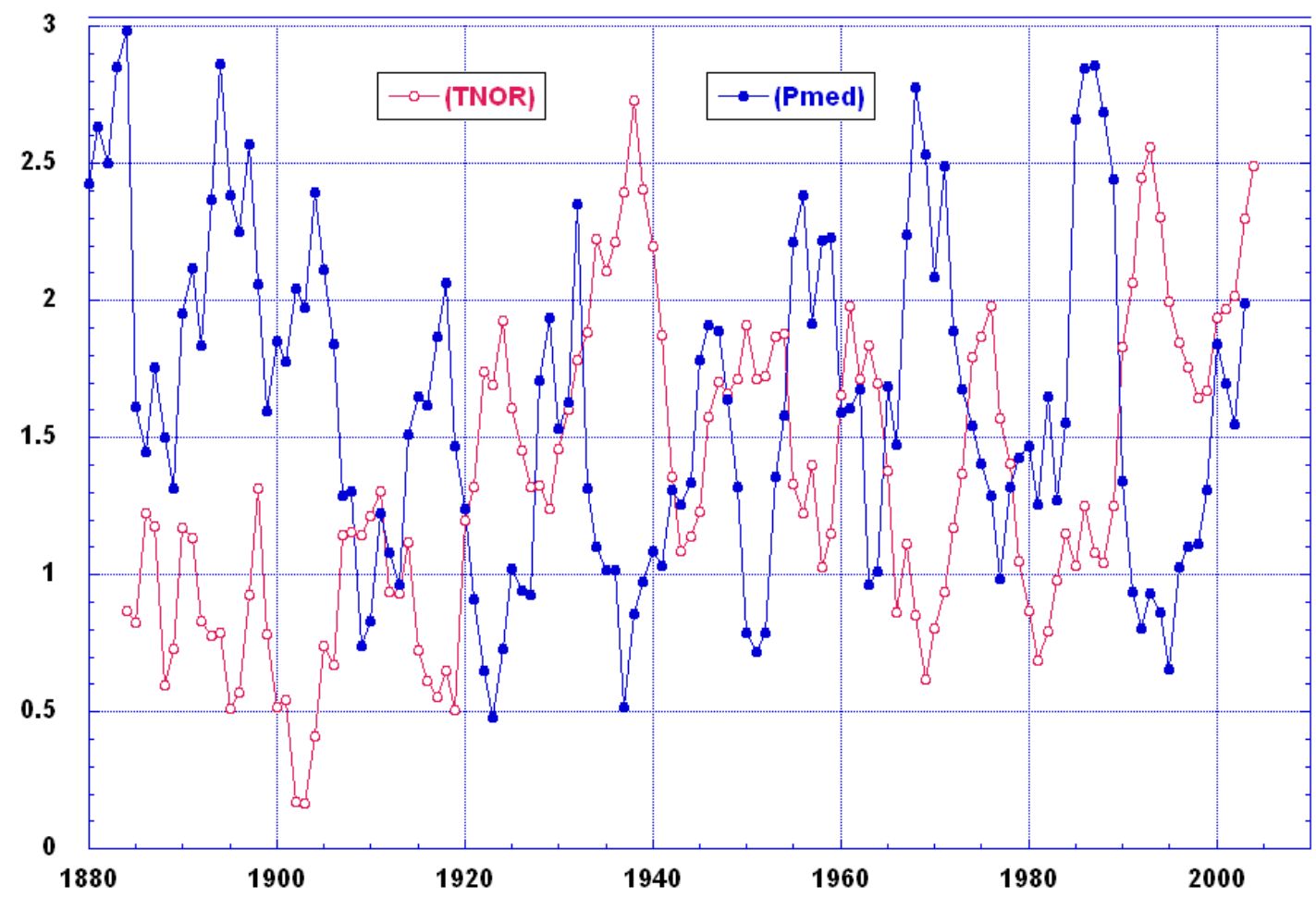

Figure 12. Thermal evolution through moving averages of 5 years (smoothed, in red) of the subpolar observatories (in Iceland, Akureyri, Teigarhorn and Stykkishólmur, in Norway, Vardo, Karasjok, Glomfjord and Longyearbyen) and of Mediterranean rainfall, with the same decrease (in blue).

\section{Energy teleconnections between Mediterranean cyclogenetic activity and North Atlantic SST}

As described above, we see that a proper description of the sea surface temperature field is needed in the numerical models for weather forecasting. These models, with increasing accuracy in the vertical description of the atmosphere, require a satisfactory parameterization of ocean-atmosphere exchanges in the atmospheric boundary layer (Ratier, 1986). This is one of the main challenges today, to which highresolution satellite imagery provides new information (Merle and Tourre, 1983).

This key role of the sea thermal field seems to respond to one of the main events or physical features of the ocean, its high heating capacity and conductivity, which are much higher than that of the air. These properties make the SST a highly significant value for the global state of energy. The presence of large anomalies reflects the accumulation of such latitudinal surpluses or deficits of heat that are at the base of the big alterations in general circulation. Through them, the atmosphere seems to behave like a giant condenser that through the expulsion of polar or tropical air is to restore energy balance on a large scale. This is an adjustment that means taking out energy from its oceanic reservoirs to redis- tribute it atmospherically. A major mechanism in this process is evaporation, as each gram of evaporated water passes 2500 joules to the atmosphere (Figure 10).

As a result of all these energy processes, it is legitimate to consider the hypothesis that the large thermal anomalies detected in the SST could be on the same basis and origin of the great Mediterranean cyclogenesis. In this order of interactions, the trigger of atmospheric discharges appears to be the energy deficit accumulated in the polar ocean basins. Such is the process that energy teleconnections show between Mediterranean cyclogenetic activity and North Atlantic SST with an annual correlation coefficient of 0.63 . This coefficient rises to 0.74 with the smoothing by threeyear moving averages (Figure 11).

Thus, the energy drawn from the subtropical sea reservoirs is atmospherically redistributed. Thus, in Figure 12, with records from the late nineteenth century, we can observe the spread of heat to the polar troposphere via the latent heat included in the Mediterranean cyclogenesis and injected into the high circulation. The T-Student test provides a value close to 0.6 and a high significative level $(<0.0001)$ that indicates the high relation between variables. We can even verify that higher polar temperatures, with a reduction in the hemispheric temperature gradient, determine rainfall cycles with 
more severe drought events. This seems to be the case in the most recent cycle and it is opposed to the maximum rainfall in the late nineteenth century.

\section{Conclusions}

This study analyzes the key role that air-sea interactions play in the original and autarkic climatology of the western Mediterranean basin. A climate whose major atmospheric disturbances or cyclogenesis appear to be linked with thermoconvective processes triggered by the arrival of cold air masses over the warm waters of the Mediterranean.

The main objective of this study was to analyze the possibility of such polar air drains to respond to a hemispheric energy realignment process. This need for meridian thermal transfer, the main mechanism of the general circulation of the atmosphere, has been verified by varying the cycle index, $I(\lambda)$, through the records of geostrophic wind speed as well as the atmospheric temperature gradient $30-60^{\circ}$ at a $700 \mathrm{hPa}$ level, over the North Atlantic. Variations of this circulation cycle under any of the proposed indexes are a response to hemispheric or global energy status. This is an energy status that has in the SST, a highly significant value. The presence of large anomalies in the ocean-marine thermal field reflects the accumulation of latitudinal excesses or deficits of heat that are at the base of the big changes in the general circulation.

The correlations found between the polar North Atlantic SST and the Mediterranean rainfall cycles do not seem random. In contrast, the teleconnections analyzed between the winter SST in the polar waters of the North Atlantic and the Mediterranean rainfall cycles are highly significant. This is a teleconnection, on the hemispheric energy balance, that has been verified on the historical series of polar temperatures in the main North Atlantic observatories. This is without discounting that the same physical correlations can be verified using more complex analytical models of general circulation.

\section{References}

Alekseev, G. V. and Bagryantsev, M. V., 1987: The climate role of ocean surface temperature anomalier in the warm half of the year, Soviet Meteorology and Hidrology, 5, 52-56.

Andersson, A., Bakan, S., and Grabl, H., 2010: Satellite derived precipitation and freshwater flux variability and its dependence of the North Atlantic Oscillation, Tellus, 62, 453-468.

Bueh, C. and Nakamura, H., 2007: Scandinavian pattern and its climatic impact, Q J R Meteorol Soc, 133, 2117-2131.

Colin de Verdière, A. and Blanc, M. L., 2001: Thermal resonance of the atmosphere to SST anomalies. Implications for the Antartic circumpolar wave, Tellus, 53, 403-424.

Egger, J. and Peter-Hoinka, K., 2008: Mountain torques and synoptic systems in the Mediterranean, Q J R Meteorol Soc, 134, 1067-1081.
Feldstein, S. B., 2007: The dynamics of the North Atlantic Oscillation during the summer season, Q J R Meteorol Soc, 133, 15891518.

Gulev, S. K., Zuleva, O., and Reva, Y., 2000: Synoptic and subsynoptic variability in the North Atlantic as revealed by the Ocean Weather Station data, Tellus, 52, 323-339.

Jansà Guardiola, J. M., 1951: Previsión del tiempo en el Mediterráneo occidental, Revista de Geofísica, 39, 234-256.

Jansà Guardiola, J. M., 1966: La Meteorología en el Mediterráneo Occidental, Tercer Ciclo de Conferencias, I.N.M, pp. 1-35.

Kazmin, A., Zatsepin, A. G., and Kontoyianis, H., 2009: Comparative analysis of the long-term variability of winter surface temperature in the Black and Aegean Seas during 1982-2004 associated with the large scale atmospheric forcing, Int J Climatol, 30, 1349-1359.

Kidson, J. W., 1985: Index cycles in the Northern Hemisphere during the Global Weather Experiment, Mon Weather Rev, 113, 607-623.

Lejenas, H. and Okland, H., 1983: Characteristics of Northern Hemisphere blocking as determined from a long-time series of observational data, Tellus, 35, 350-362.

Marshall, J., Kushnir, Y., Battisti, B., Chang, P., Czaja, A., Dickson, R., Hurrell, J., McCartney, M., Saravanan, R., and Visbeck, M., 2002: North Atlantic climate variability phenomena, impacts and mecanisms, Int J Climatol, 21, 1863-1898.

Martín-Vide, J. and Fernández-Belmonte, D., 2001: El índice NAO y la precipitación mensual en la España peninsular, Investigaciones Geográficas, Instituto Universitario de Geografía, Universidad de Alicante, 26, 45-58.

Martín-Vide, J. and López-Bustins, J. A., 2006: The Western Mediteranean Oscillation and rainfall in the Iberian Peninsula, Int $\mathbf{J}$ Climatol, 26, 1455-1475.

Merle, J. and Tourre, Y., 1983: Le bilan energétique à l'interface airmer, La Météorologie, VI, 51-68.

Namias, J., 1987: Factors relating to the explosive North Atlantic cyclone of December 1986, Weather, 42, 323-326.

Namias, J., 1989: Anomalous climatological background of the storm of 15-16 October 1987, Weather, 44, 98-104.

NCAR, 2010: Monthly Northern Hemisphere 72x19 Tropospheric Analyses, continuing from April 1947, National Center for Atmospheric Research, Boulder, Colorado, ds085.1, Research Data Archive, http://dss.ucar.edu.

Noussier, O., Ducrocq, V., and Ricard, C., 2008: A numerical study of three catastrophic precipitations events over souther France, Q J R Meteorol Soc, 134, 111-130.

Quereda-Sala, J., 1986: Un aspect du regime thermique en Mediterranée Occidentale, Met Mar, 131, 13-18.

Quereda-Sala, J., 1989a: Blocage et goutte froide sur le Levant espagnol, La Météorologie, VII, 2-7.

Quereda-Sala, J., 1989b: Las interacciones atmósfera-océano en la climatología del Mediterráneo Occidental, Avenidas fluviales e inundaciones en la cuenca del Mediterráneo, Caja de Ahorros del Mediterráneo e Instituto Universitario de Geografía de la Universidad de Alicante, pp. 67-90.

Quereda-Sala, J., 1990: Intense Cyclones in the Spanish Mediterranean, Weather, 45, 278-279.

Quereda-Sala, J. and Montón, E., 1994: Las lluvias torrenciales en la Comunidad Valenciana. Interacciones atmósfera-mar, Col·lecció Universitària, Diputacció de Castelló, Castelló, 190 pp.

Ratier, A., 1986: Temperature de la mer et analyse objective, Met 
Mar, 130, 12-17.

Rayner, N. A., Brohan, P., Parker, D. E., Folland, C. K., Kennedy, J. J., Vanicek, M., Ansell, T., and Tett, S. F. B., 2006: Improved analyses of changes and uncertainties in sea surface temperature measured in situ since the mid-nineteenth century: the HadSST2 dataset, J Climate, 19, 446-469, http://hadobs.metoffice.com/ hadsst2/index.html.

Rodwell, M. J. and Folland, C. K., 2002: Atlantic aire-sea interaction and seasonal predictability, Q J R Meteorol Soc, 128, 14131443.

Stephenson, D., Pavan, V., and Bojarin, R., 2000: Is de North Atlantic Oscillation a random walk?, Int J Climatol, 20, 1-18.

Stringer, E., 1972: Foundations of Climatology, W. H. Freeman, San Francisco, 586 pp.

Strong, C. and Davis, R., 2007: Winter jet stream trends over the Northern Hemisphere, Q J R Meteorol Soc, 133, 2109-2115.

The UNESCO/WMO Seminar on Mediterranean Synoptic, 1958: Meteorologische Abhandlungen, Band IX, Heft 1, Institut fur Meteorologia and Geophysik der Frein Universitat Berlin, Roma.

Trigo, R. M., Pozo-Vázquez, D., Osborn, T. J., Castro-Díez, Y., Gámiz-Fortis, S., and Esteban-Parra, M. J., 2004: North Atlantic Oscillation influence on precipitation, river flow and water resources in the Iberian Peninsula, Int J Climatol, 24, 925-944.

Visbeck, M. H., Hurrell, J. W., Polvani, L., and Cullen, H. M., 2001: The North Atlantic Oscillation: Past, present and future, Proc Natl Acad Sci USA, 98, 12 876-12 877.

Vonder Haar, T. H. and Oort, A. H., 1973: New estimate of annual poleward energy transport by northern hemisphere oceans, J Phys Oceanogr, 3, 169-172.

Watanabe, M. and Kimoto, M., 2006: Atmosphere-ocean coupling in the North Atlantic: a positive feedback, Q J R Meteorol Soc, 126, 3343-3369.

Zeng-Zeng, H. U. and Zhaohua, W. U., 2004: The intensification and shift of the annual North Atlantic Oscillation in a global warming scenario simulation, Tellus A, 56, 90-112. 